\title{
Lung cancers and pulmonary nodules detected by computed tomography scan: a population-level analysis of screening cohorts
}

\author{
Caichen $\mathrm{Li}^{1 \#}$, Jing Liao" ${ }^{2 \#}$, Bo Cheng ${ }^{1 \#}$, Jianfu $\mathrm{Li}^{1 \#}$, Hengrui Liang ${ }^{1}$, Yu Jiang ${ }^{3}$, Zixuan Su ${ }^{3}$, Shan Xiong ${ }^{1}$, \\ Feng Zhu ${ }^{1}$, Yi Zhao', Ran Zhong ${ }^{1}$, Feng Li ${ }^{1}$, Jianxing He ${ }^{1}$, Wenhua Liang ${ }^{1,4}$
}

${ }^{1}$ Department of Thoracic Surgery and Oncology, The First Affiliated Hospital of Guangzhou Medical University, Guangzhou Institute of Respiratory Heath \& China State Key Laboratory of Respiratory Disease \& National Clinical Research Center for Respiratory Disease, Guangzhou, China; ${ }^{2}$ State Key Laboratory of Respiratory Disease, National Clinical Research Center for Respiratory Disease, Guangdong Key Laboratory of Vascular Disease, Guangzhou Institute of Respiratory Health, The First Affiliated Hospital of Guangzhou Medical University, Guangzhou, China; ${ }^{3}$ Nanshan School, Guangzhou Medical University, Guangzhou, China; ${ }^{4}$ Department of Oncology, The First People’s Hospital of Zhaoqing, Zhaoqing, China Contributions: (I) Conception and design: W Liang, J He, C Li; (II) Administrative support: W Liang, J He; (III) Provision of study materials or patients: Caichen Li, Jing Liao, B Cheng, J Li; (IV) Collection and assembly of data: C Li, J Liao, B Cheng, J Li, H Liang, Y Jiang, Z Su; (V) Data analysis and interpretation: J Liao, B Cheng, J Li, S Xiong, F Zhu, Y Zhao, R Zhong, F Li; (VI) Manuscript writing: All authors; (VII) Final approval of manuscript: All authors.

"These authors contributed equally to this work as joint senior authors.

Correspondence to: Wenhua Liang, MD. Department of Thoracic Surgery and Oncology, The First Affiliated Hospital of Guangzhou Medical University, Guangzhou Institute of Respiratory Heath \& China State Key Laboratory of Respiratory Disease \& National Clinical Research Center for Respiratory Disease, No. 151, Yanjiang Rd, Guangzhou 510120, China. Email: liangwh1987@163.com; Jianxing He, MD, PhD. Department of Thoracic Surgery and Oncology, The First Affiliated Hospital of Guangzhou Medical University, Guangzhou Institute of Respiratory Heath \& China State Key Laboratory of Respiratory Disease \& National Clinical Research Center for Respiratory Disease, No. 151, Yanjiang Rd, Guangzhou 510120, China. Email: drjianxing.he@gmail.com.

Background: An increasing number and proportion of younger lung cancer patients have been observed worldwide, raising concerns on the optimal age to begin screening. This study aimed to investigate the association between age and findings in initial CT scans.

Methods: We searched for low-dose CT screening cohorts from electronic databases. Single-arm syntheses weighted by sample size were performed to calculate the detection rates of pulmonary nodules, lung cancers (all stages and stage I), and the proportion of stage I diseases in lung cancers. In addition, we included patients who underwent chest CT in our center as a supplementary cohort. The correlation between the detection rates and age was evaluated by the Pearson Correlation Coefficient.

Results: A total of 37 studies involving 163,442 participants were included. We found the detection rates of pulmonary nodules and lung cancers increased with age. However, the proportion of stage I diseases in lung cancers declined with increased starting age and was significantly higher in the 40-year group than in other groups ( 40 vs. $45,50,55, \mathrm{P}<0.001)$. In addition, the ratio of early-stage lung cancer to the number of nodules declined with age. Similarly, in our center, the detection rates of nodules $\left(\mathrm{R}^{2}=0.86, \mathrm{P} \leq 0.001\right)$, all lung cancer $\left(\mathrm{R}^{2}=0.99, \mathrm{P} \leq 0.001\right)$ and stage $\mathrm{I}$ diseases $\left(\mathrm{R}^{2}=0.87, \mathrm{P}=0.001\right)$ increased with age, while the proportion of stage $\mathrm{I}$ diseases consistently declined with age $\left(\mathrm{R}^{2}=0.97, \mathrm{P} \leq 0.001\right)$.

Conclusions: Starting lung cancer screening at an earlier age is associated with a higher probability of identifying a curable disease, urging future research to determine the optimal starting age.

Keywords: Lung cancer; early stage; screening; age; cure

Submitted Jul 08, 2020. Accepted for publication Dec 21, 2020.

doi: $10.21037 / \mathrm{atm}-20-5210$

View this article at: http://dx.doi.org/10.21037/atm-20-5210 


\section{Introduction}

Lung cancer was the most commonly diagnosed cancer and the leading cause of cancer-related deaths worldwide, with 2.1 million new lung cancer cases and 1.8 million deaths predicted in 2018 (1). Over the past two decades, lung cancer death rates have declined due to tobacco control programs (2). But lung cancer mortality remains high as more than half of patients are diagnosed at a late stage $(2,3)$. Lung cancer screening may be an effective strategy to detect early-stage cancers, enable timely treatments, and benefit patients significantly $(4,5)$. In the 1980 s, chest radiograph and sputum cytology become the most common screening methods for lung cancer but failed to bring benefits in the reduction of disease-specific mortality (6-12).

In the 1990s, low-dose computed tomography (LDCT) examination was considered as a potential screening tool due to its advantage of lower dosage levels than standard CT while still revealing pulmonary nodules and diagnosing lung cancers (13). In recent years, the results of the United States National Lung Screening Trial (NLST) indicated that individuals from 55 to 74 years of age with high-risk factors randomly assigned to screening with LDCT could reduce lung cancer mortality by $20 \%$ when compared with conventional chest radiography. Accordingly, the National Comprehensive Cancer Network (NCCN) (14), United States Preventative Services Task Force (USPSTF), and American Cancer Society (ACS) recommended that high-risk individuals should start lung cancer screening with LDCT $(15,16)$. Thus, LDCT became the standard screening approach for lung cancer (17).

In the previous randomized clinical trials (RCTs) and single-arm prospective cohort studies, the initial screening age for lung cancer was mostly 50 or 55 in Europe and the United States (17-23), but was 40 or 45 in some Asian studies (24-27). In recent years, an increasing number and proportion of younger lung cancer patients have been observed worldwide (28-30). Such individuals are not covered by the current guidelines for screening candidates. Thus, they may be left out of ongoing screening projects. The target population for screening needs to be more accurate regarding the optimal starting age. To date, the relationship between an earlier age and the initial CT scan results is unclear, as few programs set the starting screening age before 40. Understanding the CT scan results (e.g., the association between age and lung cancer) will help develop a detailed screening strategy. In this study, we summarized the results of lung cancer screening trials with LDCT. In addition, we included patients who underwent a chest CT scan in our center as a supplementary cohort. We present the following article in accordance with the PRISMA reporting checklist (available at http://dx.doi.org/10.21037/ atm-20-5210).

\section{Methods}

This study is registered with PROSPERO, number CRD42019128394.

\section{Literature search and selection}

A systematic and comprehensive literature search of electronic databases PubMed, Web of Science, Embase, and Cochrane Library was performed to identify the relevant studies published before October 2020, using a combination of keywords "lung cancer", "screening", and "low-dose computed tomography". RCTs and cohort studies of LDCT screening for lung cancer in populations of smokers (current and former) and non-smokers were included. Studies that focused on populations with some specific risk factors of lung cancer, such as exposure to asbestos or radiation or chronic obstructive pulmonary disease were excluded. Retrospective studies, studies that started screening after the age of 55, studies using risk models to screen populations, and studies without necessary data such as the number of baseline stage I diseases or nodules were excluded.

\section{Data extraction}

Data were extracted independently by two reviewers ( $\mathrm{Li} \mathrm{C}$ and Liao J) and were resolved by a third reviewer (Cheng B). The number of participants, pulmonary nodules, lung cancers (each stage and in total) in baseline and followup detection were extracted from eligible studies. The first author, country of origin, starting age for screening, smoking status of the population, and type of study design in each study were also extracted for further analysis. Subgroup analysis was performed according to smoking status.

\section{Statistical analysis}

The detection rates of all lung cancer cases, stage I-IV diseases, and the ratio of stage I diseases to all nodules and lung cancers were calculated using single-arm syntheses 
weighted by sample size, and Open Meta [Analyst] software (Accessed at http://www.cebm.brown.edu/openmeta/ download.html) was used for quantitative data synthesis. The Chi-square test of independence was used to compare the detection rates between different age groups under Bonferroni adjustment (starting age of each group as the independent variable, total participants of each group as the denominator). The analysis was performed using SPSS version 23.0.

\section{Patient selection and CT examination data in our center}

Patients from age 18 to 69 who underwent a chest CT scan in our hospital for identifying the causes of disease (such as medical examination, screening) between April 2014 and May 2018 were eligible for analysis as a supplementary cohort. Of particular interest was the subgroup analysis of patients before the age of 40 , as such data were rarely reported. Follow-up scans for positive findings were excluded. The detection rates of pulmonary nodules, lung cancer (in all stages and stage I), and the proportion of stage I diseases were analyzed. The correlation between detection rates and age was evaluated by the Pearson Correlation Coefficient. The analysis was performed using SPSS version 23.0.

\section{Ethical Statement}

The study was conducted in accordance with the Declaration of Helsinki (as revised in 2013). The study was approved by the ethics committee of The First Affiliated Hospital of Guangzhou Medical University (Registration number: kls2015-25). Considering that the study was a retrospective analysis, informed consent of all patients was waived by the ethics committee.

\section{Results}

\section{Study selection}

We identified 3,866 relevant records according to the aforementioned search strategy. Finally, a total of 37 studies involving 163,442 participants were included in our study, containing $10 \mathrm{RCTs}$ and 27 cohort studies. One study started screening at 35 years of age (31), seven studies started screening at 40 years of age $(4,24,25,32-35)$, three studies at 45 years of age $(26,27,36)$, sixteen studies at 50 years of age (18-21,37-48), and ten studies at 55 years of age $(17,22,23,49-55)$. The starting age for lung cancer screening varied from country to country. The flow chart and the main characteristics of each study were summarized in Figure 1, Table 1, and in total online: https://cdn.amegroups. cn/static/public/atm-20-5210-1.pdf, respectively.

\section{Association between starting screening age and CT findings in prevalent round}

A total of 31 screening programs reported the baseline results of 143,813 individuals in all lung cancer cases and stage I diseases. As expected, the detection rates of all lung cancer and stage I diseases increased with age. However, the proportion of stage I diseases declined with age and was significantly higher in the 40-year group than other age groups (40 vs. $45,50,55, \mathrm{P}<0.001$ ). Meanwhile, similar trends were observed in the ratio of early lung cancer to all nodules being detected ( 40 vs. 45, 50, 55, $\mathrm{P}<0.001)$. Figure 2 summarized the pooled results.

\section{Association between starting screening age and CT findings in follow-up scans}

Subsequently, a total of 29 screening programs reported the follow-up scan results of 124,295 individuals in all lung cancer cases, and stage I diseases were analyzed. The detection rates of lung cancer and stage I diseases increased with age, while the proportion of stage I diseases declined with age; the differences were statistically significant among the various groups ( 40 vs. $45, \mathrm{P}=0.021,40$ vs. 50 , 55, $\mathrm{P}<0.001)$. However, since few nodule results were available in the follow-up study, we could not find the trend of the ratio of stage I diseases to all nodules. Figure S1 summarized the pooled results.

\section{Subgroup analysis according to smoking status}

In the smokers (current or former) subgroup, the proportion of stage I also declined with age in both baseline and followup results. The ratio of stage I to all nodules was the highest in the 40- and 45-year-old group in baseline and followup, respectively. However, no similar trend was found in the unfiltered population subgroup due to limited literature.

\section{The findings of CT scans in different age groups in our center}

A total of 12,405 CT scans were performed from April 2014 to May 2018 in our center, and 1,871 lung cancers were 


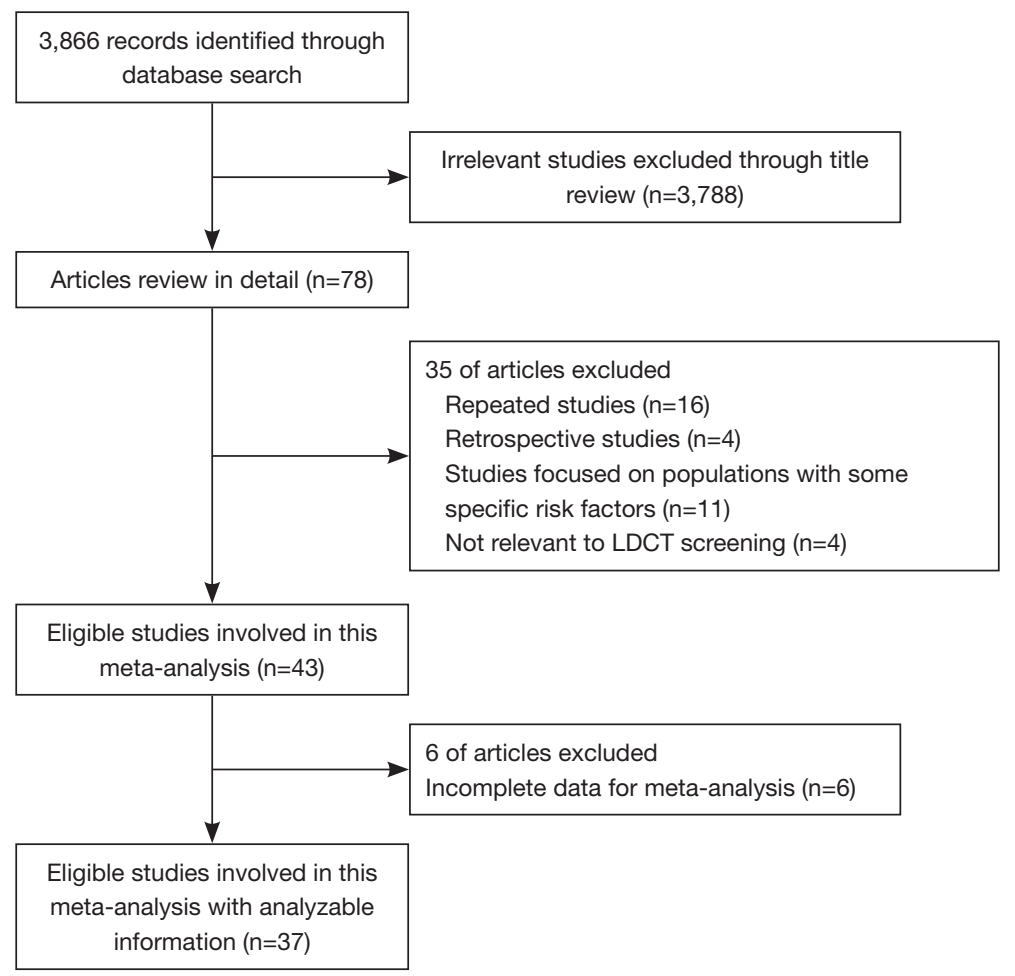

Figure 1 Flow chart of the studies included.

detected. The baseline characteristics of the population were described in Table 2. In our center, the detection rates of nodules $\left(R^{2}=0.86, P \leq 0.001\right)$, all lung cancer $\left(R^{2}=0.99\right.$, $\mathrm{P} \leq 0.001)$, and stage $\mathrm{I}$ diseases $\left(\mathrm{R}^{2}=0.87, \mathrm{P}=0.001\right)$ increased with age (Figure 3). The detection rate of lung cancer was significantly lower in the 30-34 group compared to the 4044 group $(7.37 \%$ vs. $12.00 \%, \mathrm{P}=0.002)$, but was comparable between the 35-39 and the 40-44 group (10.36\% vs. $12.00 \%, \mathrm{P}=0.284)$. Notably, the proportion of stage I diseases consistently declined with age $\left(\mathrm{R}^{2}=0.97, \mathrm{P} \leq 0.001\right)$ (Figure 3).

\section{Discussion}

This is a population-level study to investigate the association between age and findings in initial CT scans. In this study, we found that the detection rates of all lung cancer and stage I diseases were highest in the 55-year starting group compared with other groups. However, the proportion of stage I diseases was highest in the age 40-year starting group in baseline screens and follow-up scans.

Because few RCTs or cohort studies carried out CT screening before the age of 40 , we analyzed the baseline results with CTs in our hospital. And 135 individuals were diagnosed with lung cancer before age 40 after the CT examination. Furthermore, there was no statistically significant difference in the proportion of stage I diseases between the age 40-44 group and age 35-39 group, suggesting that a meaningful proportion of lung cancers might remain latent during this period and thus those with latent lung cancer at age 35-39 or age 40-44 may share similar outcomes under therapy. Therefore, the evidence is still insufficient to support initiating lung cancer screening before the age of 35 , especially when considering the costeffectiveness. It is noteworthy that our supplementary cohort mainly represented people who came to our hospital for a routine checkup or presented with mild symptoms. This could explain the different detection rates between the cohort of our center and screening cohort of populationlevel analysis.

The lung cancer screening aims to detect, diagnose and cure lung cancer in the early stage, which contributes to reducing lung cancer-related mortality with relatively limited harm, with the ultimate purpose of preventing death from lung cancer and prolonging life. Although NLST has achieved great success, some patients diagnosed through 


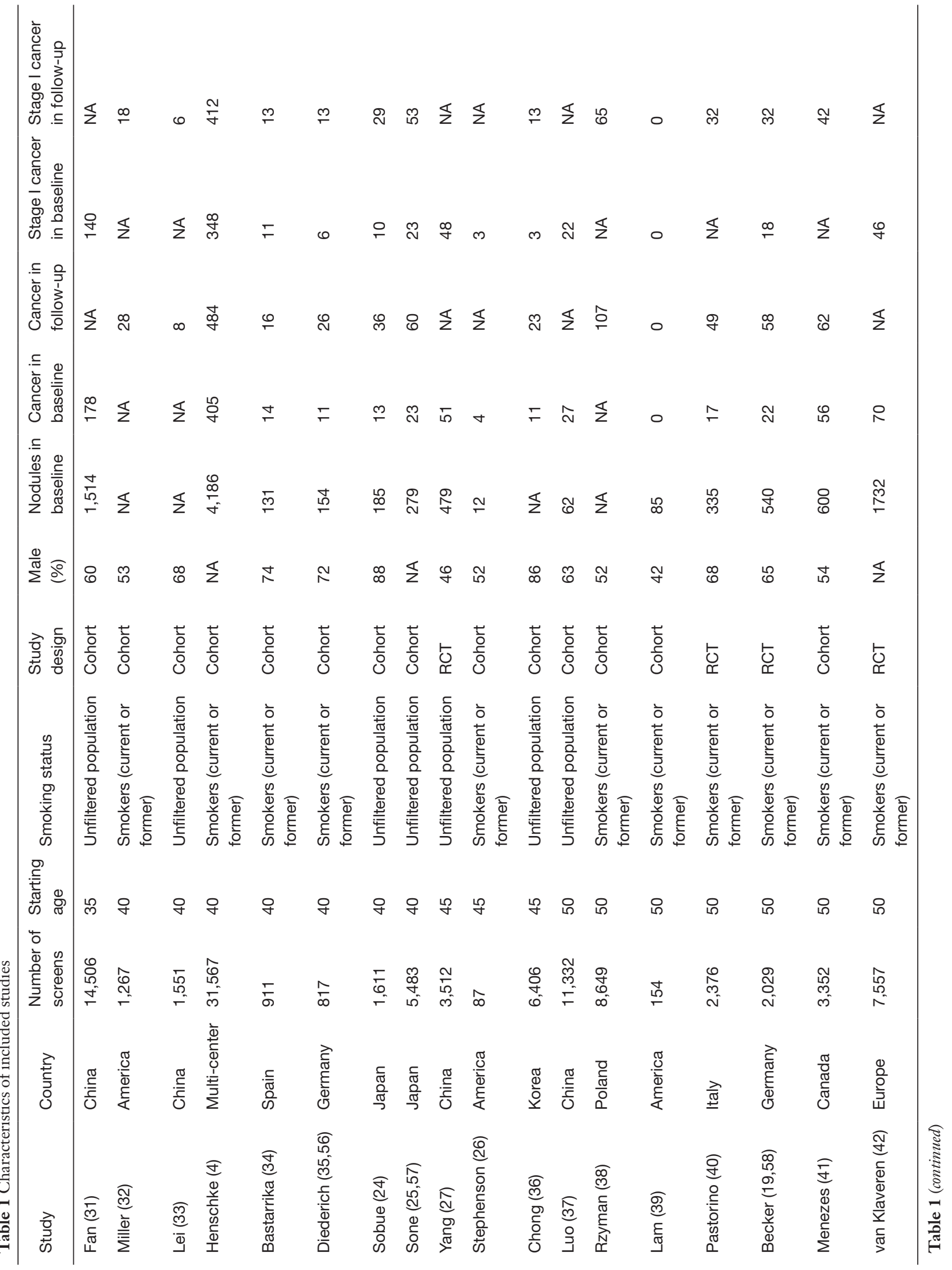




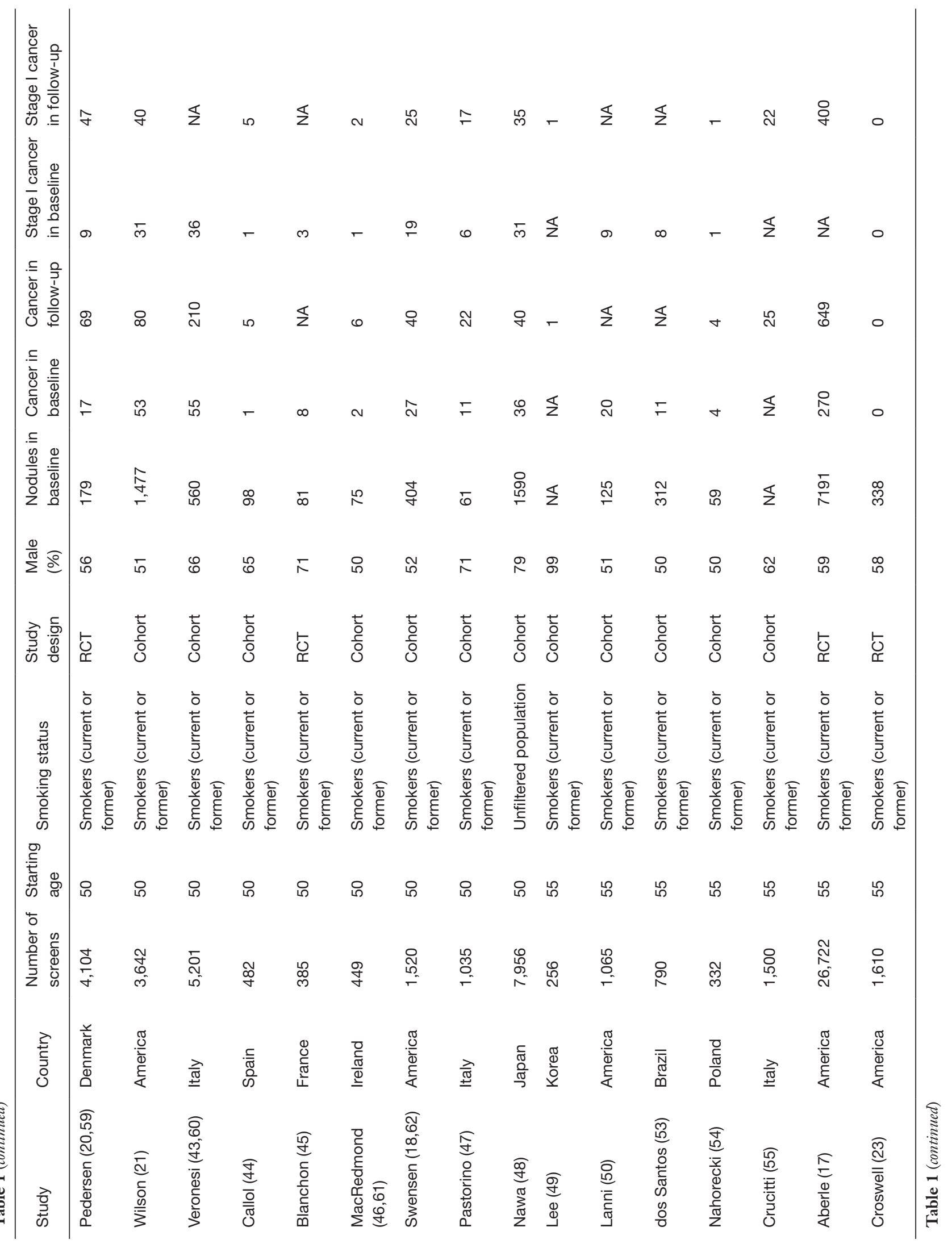




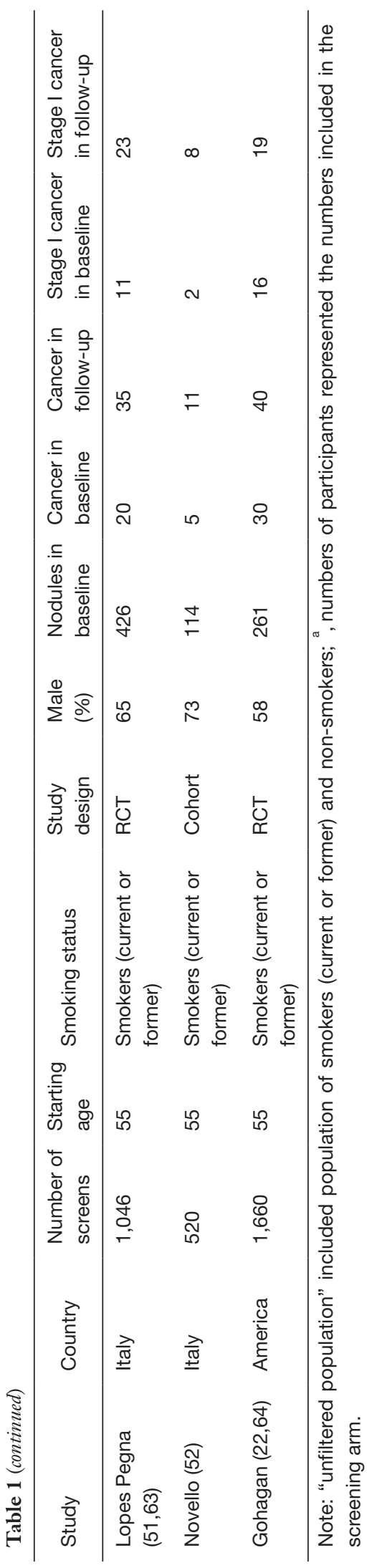

LDCT cannot be cured because of advanced cancer. In fact, the starting age for screening used by the previous studies or guidelines was determined mainly by the point when the incidence of lung cancer significantly increased in the trend over age. There was a bias in the age of diagnosis. In the past, most cases of lung cancer were found by chest $\mathrm{X}$-rays or by severe symptoms. At this time, it is too late for a large proportion of these patients to receive curative treatment. In addition, using a reliable lung-cancer risk-prediction model for individuals can identify one's cancer risk. The PanCanadian Early Detection of Lung Cancer [PanCan] model helped identify early and potentially curable lung cancer. However, the variable "age" did not show as an essential predictive factor in this model (65). Meanwhile, "age" was a continuous variable in the $\mathrm{PLCO}_{2012}$ model, according to the data of age between 55 and 74 years to develop the predictors (66). Therefore, the predictive performance outside this age range was uncertain. It is warranted to develop and validate a modal using the screening data from general population before the age of 55 .

In addition, we observed that the true positive rate (the ratio of early lung cancer to all nodules being detected) was the highest in the 40- and 45-year, followed by the 50- and 55 -year subgroup populations. Benign nodule, a barrier for differential diagnosis, was more frequently found in CT scans as age increased. This observation suggests that screening at an earlier age might simplify the diagnosis and aid clinical decisions due to a clearer background in CT; even when the CT scan in the first round does not reveal any positive nodule associated with lung cancer, it can be used for comparison with a follow-up examination in the future (67). This study indicated that a considerable number of lung cancer, and early-stage in particular, already existed in individuals at earlier ages. Thus, to diagnose more patients at an early stage of lung cancer, the age threshold for screening may require modification based on the benefits, harm, and cost-effectiveness.

In this study, we summarized the results of lung cancer screening trials with LDCT in the past few years and analyzed patients who underwent chest CT scans in our center as a supplementary cohort to investigate the association between age and findings in initial CT scans. Still, there are some limitations. First, the study's design was based on data analysis reported in the literature, and we could not access individual-level data. Second, few trials began screening at 40 years of age in European and American countries, resulting in limited data for subgroup analysis. Third, we were not able to analyze the impact 


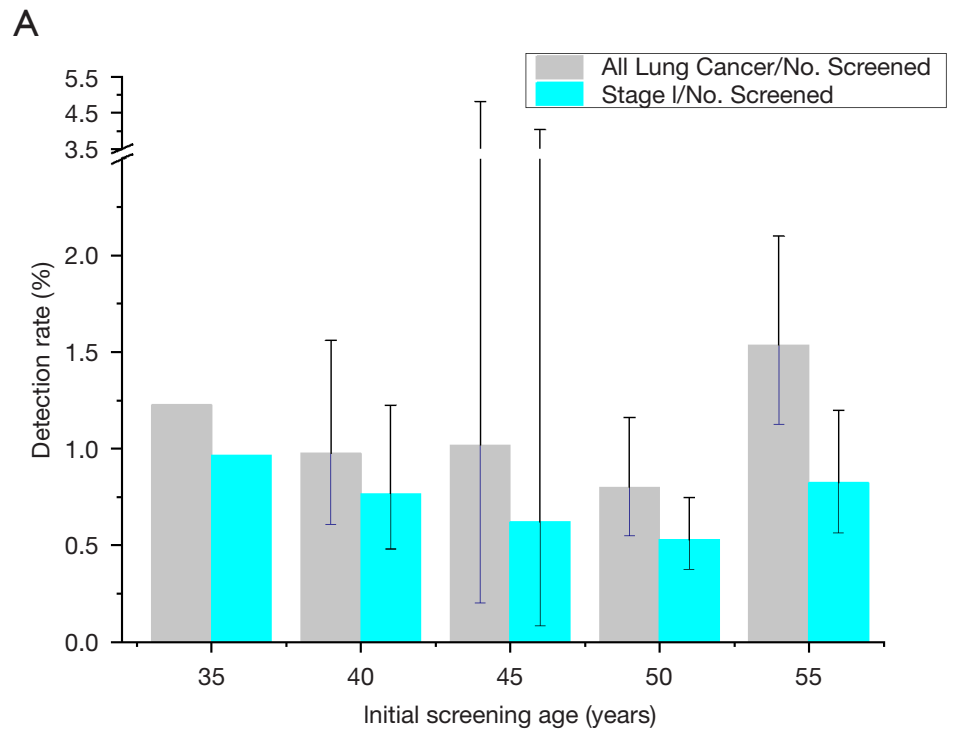

B

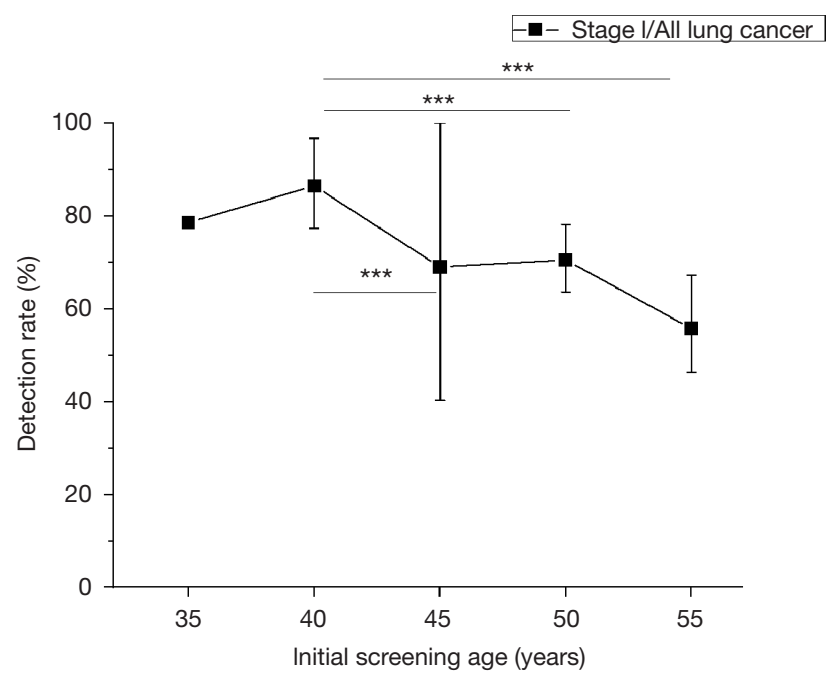

C

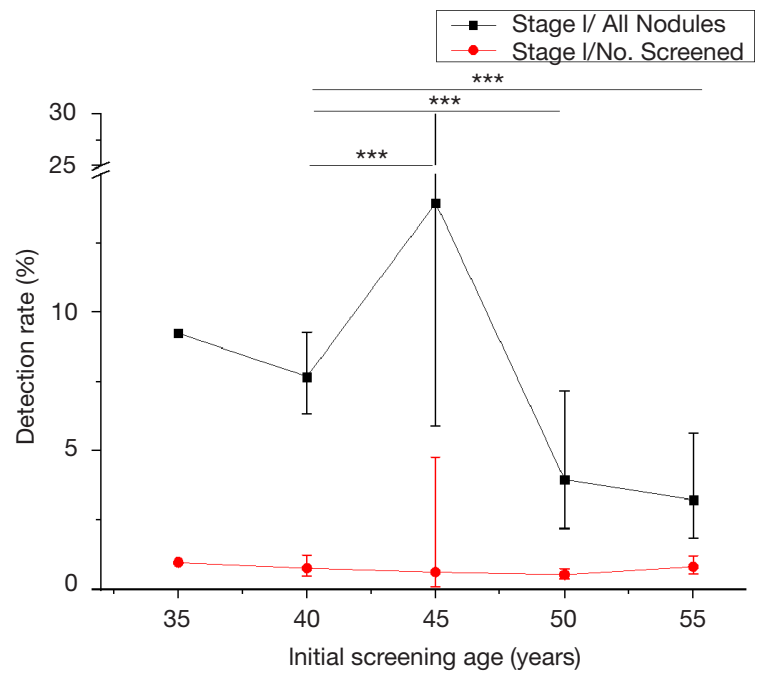

Figure 2 Baseline results in the prevalent round. The relationship between detection rates of all cancer cases and stage I diseases and initial starting age (A). The proportion of stage I diseases declined with starting age ${ }^{* * *}, \mathrm{P}<0.001$ versus $40-44$ years old) (B). The ratio of early lung cancer to all nodules declined with starting age ( ${ }^{* * *}, \mathrm{P}<0.001$ versus $40-44$ years old) (C). Vertical lines around each of the points were $95 \%$ confidence intervals.

of other high-risk factors, such as exposure to asbestos or radiation, or chronic obstructive pulmonary disease. As a result, we could not consider the possible role of covariates or logistic process regression or something similar way to analyze these data. Fourth, the LDCT settings and positivity criteria of each included study were not entirely consistent, which may affect the conclusion to some extent. In addition, showing a beneficial effect of screening is a challenge. This study did not address the impact of adverse effects by LDCT, such as the effect of overdiagnosis and radiation.

\section{Conclusions}

In summary, it is reasonable to start lung cancer screening at an earlier age than the currently recommended age for 
Table 2 Baseline characteristics and findings of CT scans in our center

\begin{tabular}{|c|c|c|c|c|c|c|c|}
\hline Characteristics & Total $(\mathrm{N}=12,405)$ & $\begin{array}{c}\text { Nodule } \\
(\mathrm{N}=4,568)\end{array}$ & $\begin{array}{l}\text { Detection rate } \\
\text { of nodule (\%) }\end{array}$ & $\begin{array}{c}\text { Lung } \\
\text { cancer(N=1,871) }\end{array}$ & $\begin{array}{l}\text { Detection rate of } \\
\text { lung cancer }(\%)\end{array}$ & Stage I $(\mathrm{N}=854)$ & $\begin{array}{l}\text { Detection rate } \\
\text { of stage I (\%) }\end{array}$ \\
\hline \multicolumn{8}{|l|}{ Sex } \\
\hline Male & 7,012 & 2,497 & & 1,003 & & 355 & \\
\hline Female & 5,393 & 2,071 & & 868 & & 499 & \\
\hline \multicolumn{8}{|l|}{ Age range } \\
\hline $18-24$ & 353 & 56 & 15.86 & 6 & 1.70 & 5 & 1.42 \\
\hline $25-29$ & 463 & 100 & 21.60 & 18 & 3.89 & 13 & 2.81 \\
\hline $30-34$ & 624 & 186 & 29.81 & 46 & 7.37 & 36 & 5.77 \\
\hline $50-54$ & 1,814 & 717 & 39.53 & 297 & 16.37 & 145 & 7.99 \\
\hline $55-59$ & 1,896 & 728 & 38.40 & 309 & 16.30 & 130 & 6.86 \\
\hline $60-64$ & 2,269 & 902 & 39.75 & 424 & 18.69 & 168 & 7.40 \\
\hline $65-69$ & 1,771 & 747 & 42.18 & 377 & 21.29 & 141 & 7.96 \\
\hline
\end{tabular}
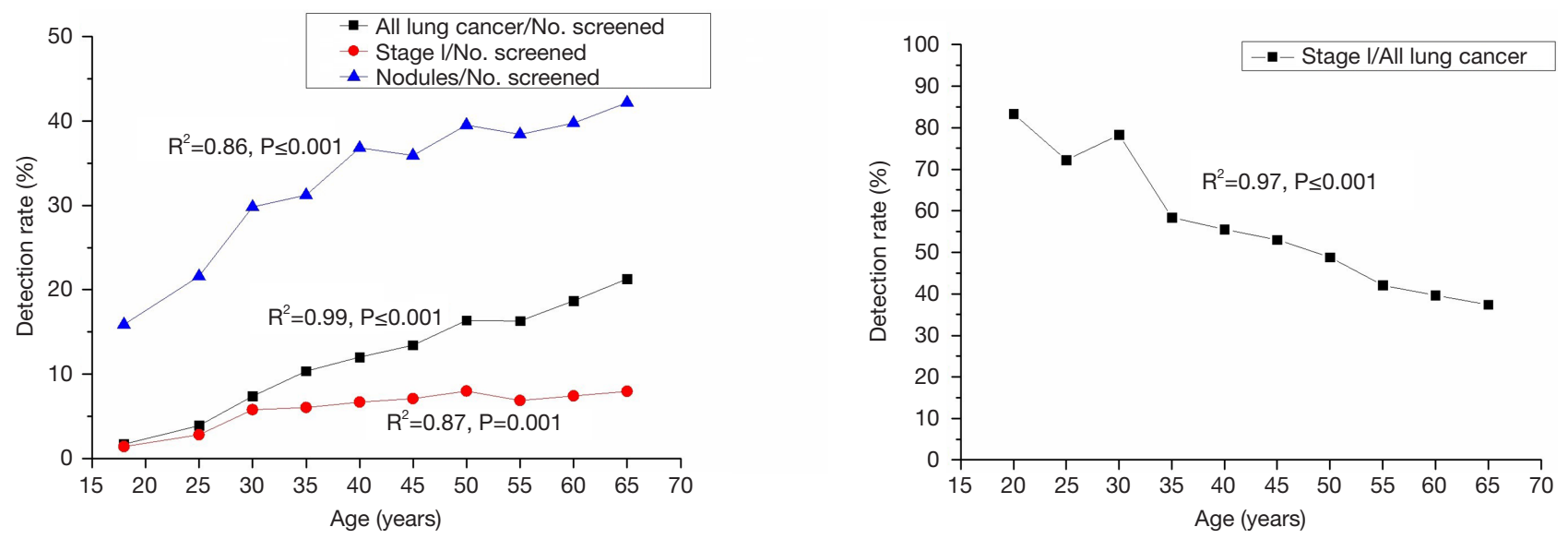

Figure 3 The findings of CT scans in different age groups in our center. The detection rates of nodules, all lung cancer, and stage I diseases increased with age, but the proportion of stage I diseases consistently declined with age.

timely detection to diagnose more patients at a curable stage of the disease. The optimal starting age requires further analyses based on original data in consideration of the survival benefits and costs and well-designed randomized controlled trials in the future.

\section{Acknowledgments}

The authors thank Ms. Lindsey Hamblin for helping to edit the manuscript.

Funding: This study was supported by the China National Science Foundation (Grant No. 81871893) and Key Project of Guangzhou Scientific Research Project (Grant No. 
201804020030).

\section{Footnote}

Reporting Checklist: The authors have completed the PRISMA reporting checklist. Available at http://dx.doi. org/10.21037/atm-20-5210

Peer Review File: Available at http://dx.doi.org/10.21037/ atm-20-5210

Data Sharing Statement: Available at http://dx.doi. org/10.21037/atm-20-5210

Conflicts of Interest: All authors have completed the ICMJE uniform disclosure form (available at http://dx.doi. org/10.21037/atm-20-5210). Prof. JH serves as an unpaid Editor-in-Chief of Annals of Translational Medicine from Jun 2019 to May 2024. The other authors have no conflicts of interest to declare.

Etbical Statement: The authors are accountable for all aspects of the work in ensuring that questions related to the accuracy or integrity of any part of the work are appropriately investigated and resolved. The study was conducted in accordance with the Declaration of Helsinki (as revised in 2013). The study was approved by the ethics committee of The First Affiliated Hospital of Guangzhou Medical University (Registration number: kls2015-25). Considering that the study was a retrospective analysis, informed consent of all patients was waived by the ethics committee.

Open Access Statement: This is an Open Access article distributed in accordance with the Creative Commons Attribution-NonCommercial-NoDerivs 4.0 International License (CC BY-NC-ND 4.0), which permits the noncommercial replication and distribution of the article with the strict proviso that no changes or edits are made and the original work is properly cited (including links to both the formal publication through the relevant DOI and the license). See: https://creativecommons.org/licenses/by-nc-nd/4.0/.

\section{References}

1. Bray F, Ferlay J, Soerjomataram I, et al. Global cancer statistics 2018: GLOBOCAN estimates of incidence and mortality worldwide for 36 cancers in 185 countries. CA
Cancer J Clin 2018;68:394-424.

2. Siegel RL, Miller KD, Jemal A. Cancer statistics, 2015. CA Cancer J Clin 2015;65:5-29.

3. Wender RC, Brawley OW, Fedewa SA, et al. A blueprint for cancer screening and early detection: Advancing screening's contribution to cancer control. CA Cancer J Clin 2019;69:50-79.

4. Henschke CI, Yankelevitz DF, Libby DM, et al. Survival of patients with stage I lung cancer detected on CT screening. N Engl J Med 2006;355:1763-71.

5. Henschke CI, International Early Lung Cancer Action Program I. Survival of patients with clinical stage I lung cancer diagnosed by computed tomography screening for lung cancer. Clin Cancer Res 2007;13:4949-50.

6. Frost JK, Ball WC, Jr., Levin ML, et al. Early lung cancer detection: results of the initial (prevalence) radiologic and cytologic screening in the Johns Hopkins study. Am Rev Respir Dis 1984;130:549-54.

7. Berlin NI, Buncher CR, Fontana RS, et al. The National Cancer Institute Cooperative Early Lung Cancer Detection Program. Results of the initial screen (prevalence). Early lung cancer detection: Introduction. Am Rev Respir Dis 1984;130:545-9.

8. Flehinger BJ, Kimmel M, Polyak T, et al. Screening for lung cancer. The Mayo Lung Project revisited. Cancer 1993;72:1573-80.

9. Melamed MR. Lung cancer screening results in the National Cancer Institute New York study. Cancer 2000;89:2356-62.

10. Kubik AK, Parkin DM, Zatloukal P. Czech Study on Lung Cancer Screening: post-trial follow-up of lung cancer deaths up to year 15 since enrollment. Cancer 2000;89:2363-8.

11. Flehinger BJ, Melamed MR, Zaman MB, et al. Early lung cancer detection: results of the initial (prevalence) radiologic and cytologic screening in the Memorial SloanKettering study. Am Rev Respir Dis 1984;130:555-60.

12. Fontana RS, Sanderson DR, Taylor WF, et al. Early lung cancer detection: results of the initial (prevalence) radiologic and cytologic screening in the Mayo Clinic study. Am Rev Respir Dis 1984;130:561-5.

13. Naidich DP, Marshall CH, Gribbin C, et al. Low-dose CT of the lungs: preliminary observations. Radiology 1990;175:729-31.

14. Wood DE, Kazerooni EA, Baum SL, et al. Lung Cancer Screening, Version 3.2018, NCCN Clinical Practice Guidelines in Oncology. J Natl Compr Canc Netw 2018;16:412-41. 
15. Moyer VA, Force USPST. Screening for lung cancer: U.S. Preventive Services Task Force recommendation statement. Ann Intern Med 2014;160:330-8.

16. Smith RA, Andrews KS, Brooks D, et al. Cancer screening in the United States, 2018: A review of current American Cancer Society guidelines and current issues in cancer screening. CA Cancer J Clin 2018;68:297-316.

17. National Lung Screening Trial Research T, Aberle DR, Adams AM, et al. Reduced lung-cancer mortality with low-dose computed tomographic screening. N Engl J Med 2011;365:395-409.

18. Swensen SJ, Jett JR, Hartman TE, et al. Lung cancer screening with CT: Mayo Clinic experience. Radiology 2003;226:756-61.

19. Becker N, Motsch E, Gross ML, et al. Randomized study on early detection of lung cancer with MSCT in Germany: study design and results of the first screening round. J Cancer Res Clin Oncol 2012;138:1475-86.

20. Pedersen JH, Ashraf H, Dirksen A, et al. The Danish randomized lung cancer CT screening trial--overall design and results of the prevalence round. J Thorac Oncol 2009;4:608-14.

21. Wilson DO, Weissfeld JL, Fuhrman CR, et al. The Pittsburgh Lung Screening Study (PLuSS): outcomes within 3 years of a first computed tomography scan. Am J Respir Crit Care Med 2008;178:956-61.

22. Gohagan J, Marcus P, Fagerstrom R, et al. Baseline findings of a randomized feasibility trial of lung cancer screening with spiral CT scan vs chest radiograph: the Lung Screening Study of the National Cancer Institute. Chest 2004;126:114-21.

23. Croswell JM, Baker SG, Marcus PM, et al. Cumulative incidence of false-positive test results in lung cancer screening: a randomized trial. Ann Intern Med 2010;152:505-12, W176-80.

24. Sobue T, Moriyama N, Kaneko M, et al. Screening for lung cancer with low-dose helical computed tomography: anti-lung cancer association project. J Clin Oncol 2002;20:911-20.

25. Sone S, Li F, Yang ZG, et al. Results of three-year mass screening programme for lung cancer using mobile lowdose spiral computed tomography scanner. Br J Cancer 2001;84:25-32.

26. Stephenson SM, Mech KF, Sardi A. Lung cancer screening with low-dose spiral computed tomography. Am Surg 2005;71:1015-7.

27. Yang W, Qian F, Teng J, et al. Community-based lung cancer screening with low-dose CT in China: Results of the baseline screening. Lung Cancer 2018;117:20-6.

28. Jemal A, Miller KD, Ma J, et al. Higher Lung Cancer Incidence in Young Women Than Young Men in the United States. N Engl J Med 2018;378:1999-2009.

29. Hong QY, Wu GM, Qian GS, et al. Prevention and management of lung cancer in China. Cancer 2015;121 Suppl 17:3080-8.

30. Zhang J, Chen SF, Zhen Y, et al. Multicenter analysis of lung cancer patients younger than 45 years in Shanghai. Cancer 2010;116:3656-62.

31. Fan L, Wang Y, Zhou Y, et al. Lung Cancer Screening with Low-Dose CT: Baseline Screening Results in Shanghai. Acad Radiol 2019;26:1283-91.

32. Miller DL, Mayfield WR, Luu TD, et al. CommunityBased Multidisciplinary Computed Tomography Screening Program Improves Lung Cancer Survival. Ann Thorac Surg 2016;101:1864-9.

33. Lei Y, Chen BJ, Zeng L, et al. Application value of lowdose computed tomography for the screening of lung cancer in high-risk group. Sichuan Da Xue Xue Bao Yi Xue Ban 2012;43:584-7.

34. Bastarrika G, Garcia-Velloso MJ, Lozano MD, et al. Early lung cancer detection using spiral computed tomography and positron emission tomography. Am J Respir Crit Care Med 2005;171:1378-83.

35. Diederich S, Wormanns D, Semik M, et al. Screening for early lung cancer with low-dose spiral CT: prevalence in 817 asymptomatic smokers. Radiology 2002;222:773-81.

36. Chong S, Lee KS, Chung MJ, et al. Lung cancer screening with low-dose helical CT in Korea: experiences at the Samsung Medical Center. J Korean Med Sci 2005;20:402-8.

37. Luo X, Zheng S, Liu Q, et al. Should Nonsmokers Be Excluded from Early Lung Cancer Screening with LowDose Spiral Computed Tomography? Community-Based Practice in Shanghai. Transl Oncol 2017;10:485-90.

38. Rzyman W, Dziedzic R, Jelitto-Gorska M, et al. Results of an open-access lung cancer screening program with lowdose computed tomography: the Gdansk experience. Pol Arch Med Wewn 2015;125:232-9.

39. Lam VK, Miller M, Dowling L, et al. Community lowdose CT lung cancer screening: a prospective cohort study. Lung 2015;193:135-9.

40. Pastorino U, Rossi M, Rosato V, et al. Annual or biennial CT screening versus observation in heavy smokers: 5 -year results of the MILD trial. Eur J Cancer Prev 2012;21:308-15.

41. Menezes RJ, Roberts HC, Paul NS, et al. Lung cancer 
screening using low-dose computed tomography in atrisk individuals: the Toronto experience. Lung Cancer 2010;67:177-83.

42. van Klaveren RJ, Oudkerk M, Prokop M, et al. Management of lung nodules detected by volume CT scanning. N Engl J Med 2009;361:2221-9.

43. Veronesi G, Bellomi M, Mulshine JL, et al. Lung cancer screening with low-dose computed tomography: a noninvasive diagnostic protocol for baseline lung nodules. Lung Cancer 2008;61:340-9.

44. Callol L, Roig F, Cuevas A, et al. Low-dose CT: a useful and accessible tool for the early diagnosis of lung cancer in selected populations. Lung Cancer 2007;56:217-21.

45. Blanchon T, Brechot JM, Grenier PA, et al. Baseline results of the Depiscan study: a French randomized pilot trial of lung cancer screening comparing low dose CT scan (LDCT) and chest X-ray (CXR). Lung Cancer 2007;58:50-8.

46. MacRedmond R, Logan PM, Lee M, et al. Screening for lung cancer using low dose CT scanning. Thorax 2004;59:237-41.

47. Pastorino U, Bellomi M, Landoni C, et al. Early lungcancer detection with spiral CT and positron emission tomography in heavy smokers: 2-year results. Lancet 2003;362:593-7.

48. Nawa T, Nakagawa T, Kusano S, et al. Lung cancer screening using low-dose spiral CT: results of baseline and 1-year follow-up studies. Chest 2002;122:15-20.

49. Lee JW, Kim HY, Goo JM, et al. Radiological Report of Pilot Study for the Korean Lung Cancer Screening (K-LUCAS) Project: Feasibility of Implementing Lung Imaging Reporting and Data System. Korean J Radiol 2018;19:803-8.

50. Lanni TB, Jr., Stevens C, Farah M, et al. Early Results From the Implementation of a Lung Cancer Screening Program: The Beaumont Health System Experience. Am J Clin Oncol 2018;41:218-22.

51. Lopes Pegna A, Picozzi G, Mascalchi M, et al. Design, recruitment and baseline results of the ITALUNG trial for lung cancer screening with low-dose CT. Lung Cancer 2009;64:34-40.

52. Novello S, Fava C, Borasio P, et al. Three-year findings of an early lung cancer detection feasibility study with lowdose spiral computed tomography in heavy smokers. Ann Oncol 2005;16:1662-6.

53. dos Santos RS, Franceschini JP, Chate RC, et al. Do Current Lung Cancer Screening Guidelines Apply for Populations With High Prevalence of Granulomatous
Disease? Results From the First Brazilian Lung Cancer Screening Trial (BRELT1). Ann Thorac Surg 2016;101:481-6; discussion 7-8.

54. Nahorecki A, Chabowski M, Kuzniar T, et al. Low-dose computer tomography as a screening tool for lung cancer in a high risk population. Adv Exp Med Biol 2015;852:31-7.

55. Crucitti P, Gallo IF, Santoro G, et al. Lung cancer screening with low dose CT: experience at Campus Bio-Medico of Rome on 1500 patients. Minerva Chir 2015;70:393-9.

56. Diederich S, Thomas M, Semik M, et al. Screening for early lung cancer with low-dose spiral computed tomography: results of annual follow-up examinations in asymptomatic smokers. Eur Radiol 2004;14:691-702.

57. Sone S, Takashima S, Li F, et al. Mass screening for lung cancer with mobile spiral computed tomography scanner. Lancet 1998;351:1242-5.

58. Becker N, Motsch E, Gross ML, et al. Randomized Study on Early Detection of Lung Cancer with MSCT in Germany: Results of the First 3 Years of Follow-up After Randomization. J Thorac Oncol 2015;10:890-6.

59. Saghir Z, Dirksen A, Ashraf H, et al. CT screening for lung cancer brings forward early disease. The randomised Danish Lung Cancer Screening Trial: status after five annual screening rounds with low-dose CT. Thorax 2012;67:296-301.

60. Veronesi G, Maisonneuve P, Spaggiari L, et al. Diagnostic performance of low-dose computed tomography screening for lung cancer over five years. J Thorac Oncol 2014;9:935-9.

61. MacRedmond R, McVey G, Lee M, et al. Screening for lung cancer using low dose CT scanning: results of 2 year follow up. Thorax 2006;61:54-6.

62. Swensen SJ, Jett JR, Hartman TE, et al. CT screening for lung cancer: five-year prospective experience. Radiology 2005;235:259-65.

63. Paci E, Puliti D, Lopes Pegna A, et al. Mortality, survival and incidence rates in the ITALUNG randomised lung cancer screening trial. Thorax 2017;72:825-31.

64. Gohagan JK, Marcus PM, Fagerstrom RM, et al. Final results of the Lung Screening Study, a randomized feasibility study of spiral CT versus chest X-ray screening for lung cancer. Lung Cancer 2005;47:9-15.

65. Tammemagi MC, Schmidt H, Martel S, et al. Participant selection for lung cancer screening by risk modelling (the Pan-Canadian Early Detection of Lung Cancer [PanCan] study): a single-arm, prospective study. Lancet Oncol 2017;18:1523-31. 
66. Tammemagi MC, Katki HA, Hocking WG, et al. Selection criteria for lung-cancer screening. N Engl J Med 2013;368:728-36.

67. MacMahon H, Naidich DP, Goo JM, et al. Guidelines for

Cite this article as: Li C, Liao J, Cheng B, Li J, Liang H, Jiang Y, Su Z, Xiong S, Zhu F, Zhao Y, Zhong R, Li F, He J, Liang W. Lung cancers and pulmonary nodules detected by computed tomography scan: a population-level analysis of screening cohorts. Ann Transl Med 2021;9(5):372. doi: 10.21037/atm-20-5210
Management of Incidental Pulmonary Nodules Detected on CT Images: From the Fleischner Society 2017. Radiology 2017;284:228-43. 


\section{Supplementary}
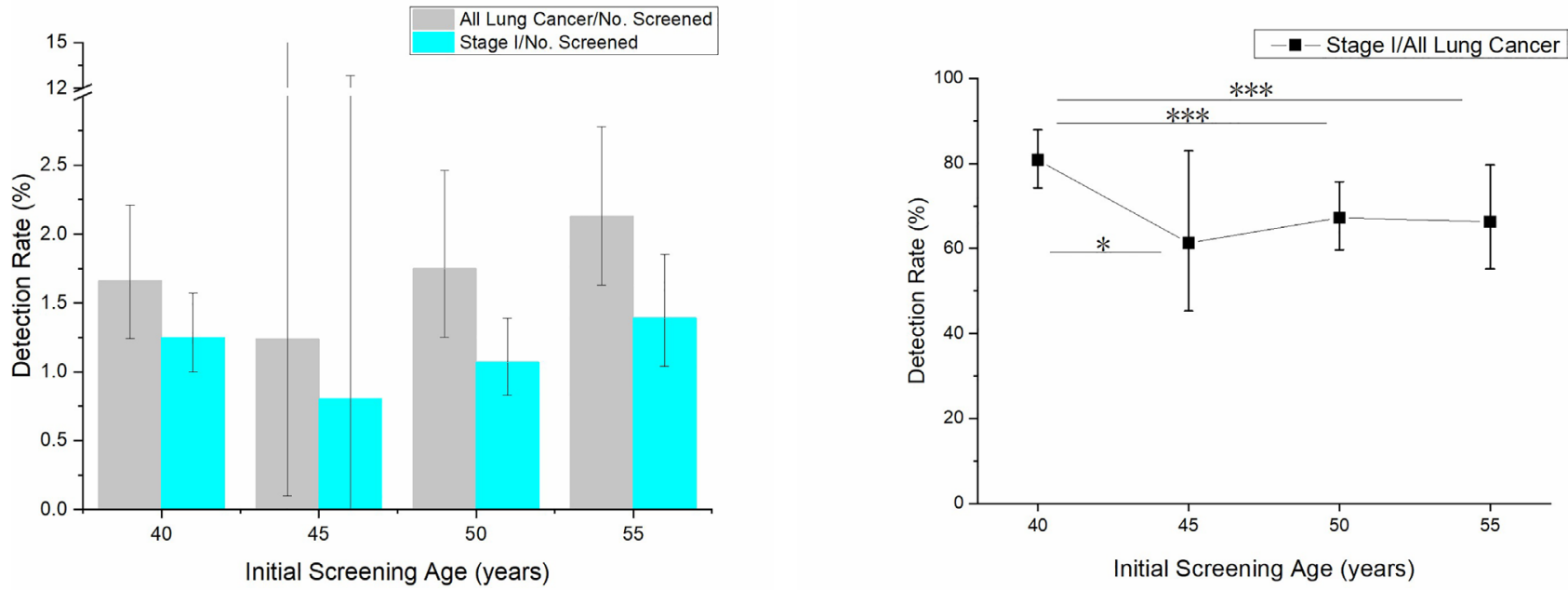

Figure S1 Follow-up scan results in incident screens. The relationship between detection rates of all cancer cases and stage I diseases and initial starting age (A). The proportion of stage I diseases declined with age ( ${ }^{*}, \mathrm{P}=0.021$ versus $40-44$ years old, ${ }^{* * *}, \mathrm{P}<0.001$ versus $40-44$ years old) (B). Vertical lines around each of the points were $95 \%$ confidence intervals. 